\title{
Post-surgical reeducation of the burned adult
}

\author{
Saloua Khalfaoui*, Abdellah El Marbouh and E1 Mustapha El Abbassi \\ Department of Physical Medicine and Rehabilitation, Military Instruction Hospital Mohammed V, Morocco
}

\begin{abstract}
The burn causes the destruction of the largest organ of the human body. Its complications are serious and can involve the vital and functional prognosis of the patient. Care takes several steps from the accident site to social, family and professional reintegration. In our article, we are interested in the post-surgical phase where retractions and hypertrophies take place, thus requiring an adequate program of rehabilitation and functional rehabilitation.
\end{abstract}

\section{Introduction}

The healing of burns goes through several stages after the postsurgical resuscitation and hemodynamic stabilization phase. The rehabilitation scheme adapts to the degree of scarring. This is where the musculo-tendinous and capsuloligamentary retractions appear and the enlargements are accentuated and it is at this point that the rehabilitation protocol intensifies [1].

In general, it takes place in three essential phases:

Phase I is intended mainly for burn patients in whom other transplant-type surgical procedures are planned (Figure 1). Discharge from the intensive care unit and admission to the physical medicine and rehabilitation service allows these patients to have fewer orthopedic complications (Figure 2), to change the bacterial flora [2], to avoid nosocomial infections and the risk of sepsis.

In addition to the physiotherapist, the nurse and the nursing assistant play a significant role in the care of scars (which must be sufficiently hydrated), bandages (which must facilitate joint mobilization, the wearing of compression garments and the positioning of postural orthoses) and bandages (which must be removed without creating pain for the patient).

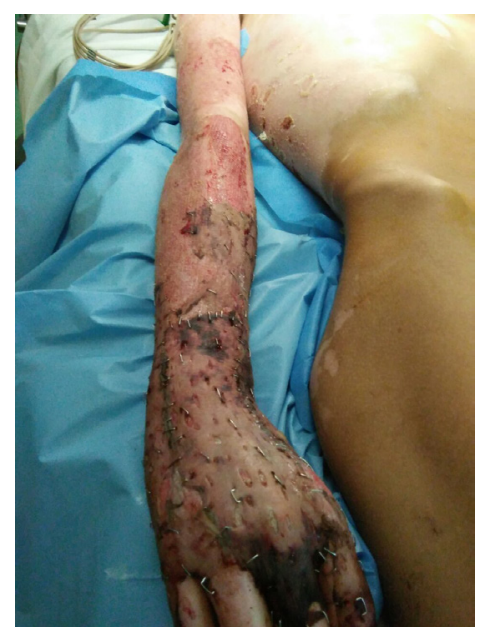

Figure 1. Hand surgery with graft type

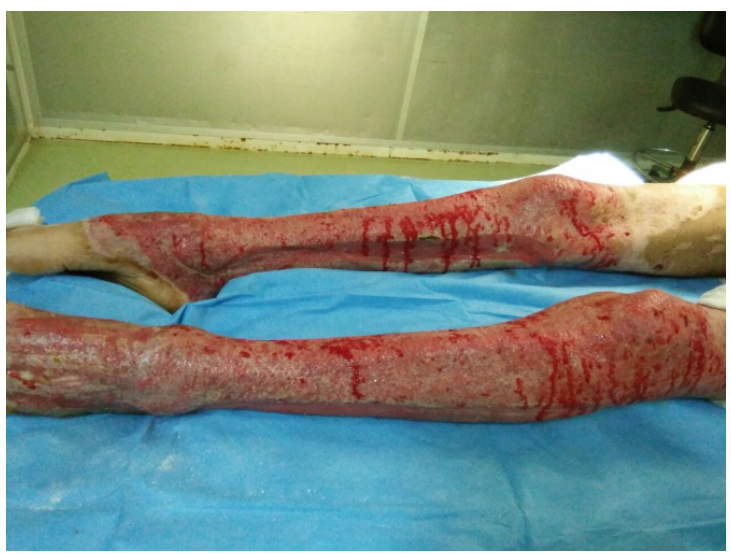

Figure 2. Orthopedic complications (bilateral equinism)

Taking the best digital photographs allows you to follow the development and healing of burned areas. It must be regular, dated and filed in a reference file.

The physiotherapist must first carry out an initial assessment which will serve as a reference to assess the degree of severity of the lesions, monitor the progress and verify the result of the methods applied.

This assessment includes:

- A cutaneous-trophic assessment specifying the appearance of the pericicatricial skin, of the scar (shape, size, depth, coloring, consistency, vascularization, adhesion to the underlying plane.

- An orthopedic assessment: based on the clinic and radiology.

- And a functional assessment.

${ }^{\star}$ Correspondence to: Saloua Khalfaoui, Professor Assistant, Mohamed V University, Faculty of Medicine and Pharmacy of Rabat, Morocco, E-mail: salaouine@hotmail.com

Key words: burn, post-surgical phase, rehabilitation

Received: June 04, 2020; Accepted: June 29, 2020; Published: July 01, 2020 
The means of rehabilitation are represented by gentle pericicatricial massage, circulatory and lymphatic drainage (manual and instrumental), the aim of which is to combat progressive edema and verticalization, which must be continued with monitoring of blood pressure. Walking work if possible, with or without human or technical assistance is necessary. Sitting and standing balance must be an integral part of this rehabilitation program as well as respiratory physiotherapy if there is bronchial congestion. The scars must be put under maximum skin stretching (whitening test). For each joint, tolerable postures must be performed in intra-pain and then globally at the end of the session. In order to maintain the result obtained during the day's session, the physiotherapist must teach the patient self-posture. The use of posture plaster is possible in the face of resistive retractions, joint limitation, constituted deformation and flanges. The plaster must be non-compressive, separated from the wound by elastic jersey with protective aim and renewed every day. Its port is limited only overnight temporarily without exceeding three nights in a row.

Regarding the hand, special attention is paid, and a separate chapter is dedicated to the rehabilitation of the burned hand.

Phase II: This is the period when burns and wounds are healed but with retractions and enlarged sequelae. The patient can leave the hospital to face his environment. This is an extremely difficult stage from a psychic point of view because the patient is faced with a new body image which he must gradually accept and end with his previous appearance. Psychological support must be part of the rehabilitation and functional rehabilitation program.

If the patient is still hospitalized, nursing care is continued but less intensely. They are summarized in the small dressings still necessary, the hygiene care and the help brought to the patient for the changes of clothes, the installation and the removal of orthotics and the spreading of moisturizers.

\section{In physiotherapy}

- Scarring massage of the burned area in the absence of inflammation [3] (use skin whitening and vitropression tests).

- Hydration, pressure-sliding and kneading by palpate-roll. In addition to the other techniques of the previous phase (joint mobilization, gain in raticular amplitudes, postures and selfpostures, etc.), analgesic physiotherapy (pulsed ultrasound, etc.) must be applied [4], joint relaxation and stretching and muscular, the overall muscular reinforcement by the Kabat technique and especially aiming at the restoration of the agonist / antagonist ratio of the muscular groups.

Filiform showers with tap water for five to ten minutes (from the third month) have multiple benefits. They fight against deep adhesions, activate blood circulation, provide general well-being, improve the appearance of the skin and prepare the patient for spa treatment.

In occupational therapy, it is the making of custom-made compression garments with elastic Lycra * fabrics. They are temporary pending longer lasting compression garments.

For the face, neck and areas of difficult accessibility, we use other compression methods such as rigid or semi-rigid orthotics, gels and silicone. In orthoprosthetics, it is the role of the appliance and the functional work: -The apparatus: [5]. It can be hand orthotics of different sizes, flexion or extension depending on the burned face or analytical or global posture. They are to be worn for an hour a day. Plaster can be used if skin tolerance and severe stiffness.

-Functional work is carried out between posture sessions with increasing complexity depending on the patient's abilities. Several techniques can be applied for this functional work with the aim of optimizing gestures and improving the use of objects by integrating desensitization techniques.

Besides these treatments, sporting activity is offered, the type, duration and purpose of which differ depending on the level of progress of the burn patient.

\section{Phase III}

It is the preparation for going out and confronting outside life. All medical and paramedical care personnel ensure that the patient is convinced of the need to continue care regarding the regular wearing of compression garments. Performing functional rehabilitation sessions. The installation of postural orthoses at the end of physiotherapy sessions, and thermal cures.

\section{Physiotherapistically}

Functional rehabilitation sessions focus mainly on active muscle work and overall, with continued fight against adhesions, retractions and vicious attitudes.

The rhythm and the frequency of the sessions adapted according to the possibilities and the scar condition of the patient. A group gymnastics-type physical activity is often recommended to encourage the patient to confront other people. Then, it is necessary to pass to the effort training in the absence of contraindication [6].

\section{On the occupational therapy level}

The patient is put in a real-life situation to gradually accustom him to overcome the obstacles and difficulties he may encounter in gestures and activities of daily life.

Also professional activities are necessary. It helps prepare the patient for socio-professional reintegration.

In general, certain precautions must be taken into consideration, such as good twice-daily hydration, eviction from exposure to the sun without clothing or sun protection, good medical follow-up in consultation and the application of certain instructions regarding make-up to better manage the new appearance.

Then, it is the outpatient and sequelae rehabilitation stage which takes place either in the day hospital or in the city office, in addition to the spa treatments which have a spectacular effect. This is a chapter for further discussion.

\section{Conclusion}

The healing of burns is not simple, and goes through several stages which require medical, paramedical and rehabilitative care adapted to the cutaneous state, the degree of evolution and the after-effects of this healing. The means available aim to reduce these consequences, compensate for the loss of autonomy and improve the new self-image. Psychological and social support is present in all stages to facilitate acceptance of the new body envelope.

\section{Conflicts of interest}

The authors declare that they have no conflicts of interest. 


\section{References}

1. Rochet JM, Wassermann D, Carsin H, Desmoulière A, Aboiron H, et al. (1998) Rééducation et réadaptation de l'adulte brûlé. Encycl Méd Chir (Elsevier, Paris), Kinésithérapie-Médecine physique-Réadaptation 26-280-C-10 : 27

2. Bournaud M, Rochet JM, Pouria JJ, Pochat MC, Charpentier P, et al. (1997) Maîtrise de la diffusion des germes multirésistants: cas d'un centre de rééducation traitant des brûlés. In : Dhennin C, Griffe O eds. Actualités de la société française d'étude et de traitement des brûlures. Montpellier : Sauramps médical 7: 41-49
3. Gavroy JP, Poveda A, Oversteyns B, Plantier G, Rougé D, et al. (1995) Intérêt du « test de vitropression » dans le suivi des cicatrices de brûlures à partir de 50 observations. Ann Medit Burns Club 7 : 28-29.

4. Rochet JM (1996) Rééducation des grands brûlés en centre de rééducation et en ambulatoire. La Lettre Du Médecin Rééducateur 39: 15-19

5. Rochet JM (1991) Les principales orthèses des mains brûlées d'adultes ; buts, conception, confection, indications [mémoire DU d'appareillage des handicapés moteurs]. Nancy : Université de Nancy 3: 1-149

6. Marichy J, Marduel YN (1988) Réducation des brûlés adultes. Encycl Med Chir (Elsevier, Paris). Kinésithérapie-Rééducation fonctionnelle, 26-275-A-10: 1-10

Copyright: $\odot 2020$ Khalfaoui S. This is an open-access article distributed under the terms of the Creative Commons Attribution License, which permits unrestricted use, distribution, and reproduction in any medium, provided the original author and source are credited. 